\title{
Association between Peak Neutrophil Count, Clopidogrel Loading Dose, and Left Ventricular Systolic Function in Patients with Primary Percutaneous Coronary Intervention
}

\author{
Xinyu Wang, ${ }^{1,2}$ Haiyi Yu, ${ }^{1,2}$ Zhaoping Li, ${ }^{1,2}$ Liuning Li, ${ }^{1,2}$ Youyi Zhang, ${ }^{1,2}$ and Wei Gao \\ ${ }^{1}$ Department of Cardiology, Institute of Vascular Medicine, Huayuanbeilu 49, Haidian District, \\ Peking University Third Hospital, Beijing 100083, China \\ ${ }^{2}$ Key Laboratory of Cardiovascular Molecular Biology and Regulatory Peptides, \\ Ministry of Health and Key Laboratory of Molecular Science, Ministry of Education, \\ and Beijing Key Laboratory of Cardiovascular Receptors Research, Beijing 100191, China \\ Correspondence should be addressed to Youyi Zhang; zhangyy@bjmu.edu.cn and Wei Gao; articlecardio@sina.cn
}

Received 6 April 2014; Revised 26 June 2014; Accepted 10 July 2014; Published 24 July 2014

Academic Editor: Pham My-Chan Dang

Copyright (C) 2014 Xinyu Wang et al. This is an open access article distributed under the Creative Commons Attribution License, which permits unrestricted use, distribution, and reproduction in any medium, provided the original work is properly cited.

Inflammation plays an important role in plaque development and left ventricular remodeling during acute myocardial infarction (AMI). Clopidogrel may exhibit some anti-inflammatory properties and high loading dose of clopidogrel results in improved clinical outcomes in patients with AMI. 357 patients who received successful primary percutaneous coronary intervention from January 2008 to March 2011 in Peking University Third Hospital were included in this study. Different loading dose of clopidogrel (300 mg, $450 \mathrm{mg}$, or $600 \mathrm{mg}$ ) was given at the discretion of the clinician. Neutrophils reached their peak values on the first day after AMI. Higher levels of peak neutrophil and lower left ventricular ejection fraction (LVEF) were found in patients of low clopidogrel loading dose group (300 mg or $450 \mathrm{mg}$ ). After adjusting for the related confounders, a logistic regression model showed that low clopidogrel loading dose remained an independent predictor of low LVEF (LVEF $\leq 50 \%$ ) [OR: 1.97, 95\% CI: 1.03-3.79, P = 0.04]. Low clopidogrel loading dose was associated with higher peak neutrophil count and poor left ventricular systolic function, suggesting an important role of clopidogrel loading dose in the improvement of left ventricular function and high loading dose may exhibit better anti-inflammatory properties.

\section{Introduction}

Inflammation plays an important role in plaque development and left ventricular remodeling during acute myocardial infarction (AMI) [1, 2]. Several studies have shown an association between elevated levels of baseline neutrophils and poor heart function in patients with AMI $[3,4]$. It has been recognized that platelet was a key contributor to initiate and propagate thrombosis and dual antiplatelet therapy with aspirin and clopidogrel has given significant benefits in patients with AMI $[5,6]$.

Evidence from clinical studies revealed that $600 \mathrm{mg}$ loading dose of clopidogrel compared with $300 \mathrm{mg}$ resulted in decreased 30-day ischemic adverse event and death rates in patients with ST-segment elevation myocardial infarction (STEMI) undergoing primary percutaneous coronary intervention (PPCI) $[7,8]$. Numerous cross-links are known to exist between the thrombotic and inflammatory pathways in the pathophysiology of acute coronary syndrome (ACS) $[1,2]$. As well, it has been proposed that clopidogrel may also exhibit some anti-inflammatory properties $[9,10]$. However, there is lack of support for the association between high loading dose of clopidogrel and heart function in patients with PPCI. And until now, it is not clear whether the higher loading dose of clopidogrel has a better anti-inflammatory effect.

The aim of this study was to establish the association of loading dose of clopidogrel and left ventricular systolic function in patients with STEMI. Earlier study showed that 
neutrophil peaked within 24 hours after the onset of STEMI [11], so we wished to examine the association between peak neutrophil count and the benefit with high loading dose of clopidogrel.

\section{Patients and Methods}

2.1. Patients. Patients with STEMI were selected from the department of cardiology at the Peking University Third Hospital over the period from January 2008 to March 2011. Permission for the study was obtained by the local ethics committee. Written informed consent was obtained from the study population. STEMI was diagnosed according to the American College of Cardiology/American Heart Association guideline in 2004. All patients received successful PPCI (defined as coronary angiography with optimized flow of TIMI grade 3 ) within $12 \mathrm{~h}$ from symptom onset. Digital angiograms were analyzed by two independent, experienced interventional cardiologists. In order to assess coronary blood flow as a continuous variable, the corrected TIMI frame count (CTFC) was determined on final angiogram as described [12]. A total of 488 consecutive patients with STEMI were enrolled. The study excluded patients with (1) infectious disease $(n=$ 44); (2) death or cardiogenic shock that happened during the hospitalization ( $n=35)$; (3) usage of antiplatelet drugs prior to the onset $(n=27)$; (4) significant kidney or hepatic diseases $(n=17)$; (5) other causes of AMI $(n=6)$; (6) malignancy $(n=2)$. Thus, 357 patients $(72.2 \%$ men, mean age $60 \pm 11.3$ years) constituted the present study.

2.2. Blood Sampling. Peripheral venous blood samples were obtained from all patients at the admission and in the morning of the first (D1), third (D3), and seventh day (D7) after STEMI $(n=357)$. The first blood sample was drawn prior to commencement of antiplatelet therapy. Blood samples were taken into standardized tubes (INSEPACK ST serials, Beijing, China) containing dipotassium ethylenediaminetetraacetate (EDTA-K2) and stored in room temperature. Total white blood cells (WBC) and neutrophils were measured $30 \mathrm{~min}$ after blood collection with an automated hematology analyzer (XE2100, Sysmex, Kobe, Japan). The reference ranges for total WBC and neutrophils are (4.0-10.0) $\times 10^{9} / \mathrm{L}$ and $(3.0-$ $5.0) \times 10^{9} / \mathrm{L}$, respectively. Blood samples for high-sensitive Creactive protein (hs-CRP) and blood lipid analysis were taken between 24 and $48 \mathrm{~h}$ after admission. In a subgroup including all of the patients admitted during October 2009 to March $2011(n=52)$, additional blood samples were collected at the admission and 4-6 h, 12 h, $24 \mathrm{~h}$, and the seventh day (D7) after PPCI. All samples were collected in vacuum blood collection tubes with clot activator and centrifuged at 3,000 rpm for $10 \mathrm{~min}$ at $4^{\circ} \mathrm{C}$. An aliquot of the serum was stored at $-80^{\circ} \mathrm{C}$ till analysis. Repeated freeze-thaw cycles were avoided.

2.3. Killip Classification. Killip class was evaluated by three clinicians during the first two days after STEMI according to the classic article [13]. Class 1: no evidence of heart failure; Class 2: signs indicating mild to moderate degree of heart failure (e.g., S3 gallop, rales < half-way up lung fields, or elevated jugular venous pressure); Class 3: pulmonary edema; and Class 4: cardiogenic shock or hypotension.

2.4. Assays. In a subgroup including all the patients admitted during October 2009 to March $2011(n=52)$, serum levels of interleukin-6 (IL-6) and interleukin-10 (IL-10) were measured by enzyme linked immunosorbent assay (ELISA) according to the manufacturer's instruction (ELISA kit, R\&D Systems, Minneapolis, MN, USA). The minimal detection limits for IL-6 and IL-10 were $0.7 \mathrm{pg} / \mathrm{mL}$ and $3.9 \mathrm{pg} / \mathrm{mL}$, respectively. These assays were performed by an investigator blinded to the sources of the samples.

2.5. Adjunctive Pharmacotherapy. All patients received $300 \mathrm{mg}$ acetylsalicylic acid before intervention and unfractionated heparin during PPCI on routine basis. Different loading dose of clopidogrel $(300 \mathrm{mg}, 450 \mathrm{mg}$, or $600 \mathrm{mg}$ ) was given at the discretion of the clinician in the emergency room within 30 minutes after admission and subsequently $75 \mathrm{mg}$ daily for the period of hospitalization. The high loading dose of clopidogrel is defined as $600 \mathrm{mg}$ and the low loading dose is defined as $300 \mathrm{mg}$ or $450 \mathrm{mg}$. The glycoprotein IIb/IIIa inhibitors (abciximab) were administered during PCI, at the discretion of the operator, as a $0.25 \mathrm{mg} / \mathrm{kg}$ bolus and a $0.125 \mathrm{ug} / \mathrm{kg} / \mathrm{min} 12-24 \mathrm{~h}$ infusion. Other drugs commonly prescribed were angiotensinconverting enzyme inhibitors (ACEIs) or angiotensin II receptor blockers (ARBs), $\beta$-blockers, statins, and isonitrate.

2.6. Echocardiography. Each patient underwent echocardiography lying in the left decubitus position during the first three days after STEMI using a GE-VingMedVechocardiographic machine (Vivid 7) with a $3.3 \mathrm{MHz}$ multiphase array probe. These examinations were performed by experienced cardiologists. The status of receiving $\beta$-blockers treatment, heart rates, and rhythm during the procedures were recorded. Left ventricular ejection fraction (LVEF) was obtained using a modified biplane version of Simpson's method with apical two- and four-chamber views. Low LVEF was defined as $\mathrm{LVEF} \leq 50 \%$. Regional wall motion abnormalities were evaluated by multiple apical and short-axis views as in routine clinical practice. The left ventricle was divided into 17 segments ( 6 basal, 6 midventricular, and 5 apical) as recommended by the American Society of Echocardiography [14]. Each segment was analyzed individually and scored by motion and systolic thickening as follows: 1 = normal/hyperkinesis, $2=$ hypokinesis, 3 = akinesis, 4 = dyskinesis, and $5=$ aneurysmal. Left ventricle wall motion score index (WMSI) was derived from the sum of all scores divided by the number of LV segments [14].

2.7. Statistics. Baseline clinical parameters between the group of low loading dose of clopidogrel and the group of high loading dose were compared using Student's unpaired $t$-tests, chi-squared tests, or Mann-Whitney test as appropriate. To test the normal distribution, the Kolmogorov-Smirnov test was used. One-way analysis of variance followed by post hoc analysis was used for comparing total WBC and neutrophils 

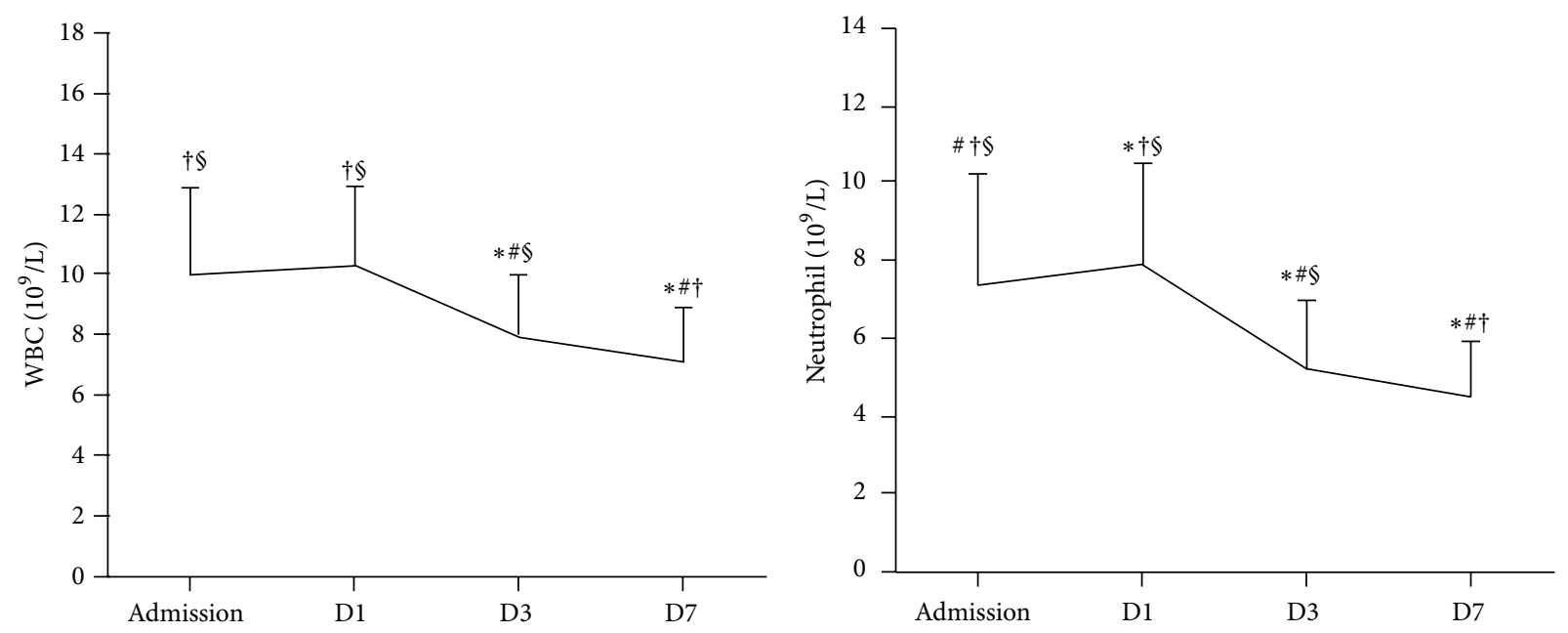

FIGURE 1: The time course of WBC and neutrophil in patients with STEMI who received successful PPCI $(n=357)$. $*$ Represents $P<0.05$ compared with admission, \# represents $P<0.05$ compared with $\mathrm{D} 1, \dagger$ represents $P<0.05$ compared with $\mathrm{D} 3$, and $\S$ represents $P<0.05$ compared with D7. Note: D1: the first day, D3: the third day, and D7: the seventh day.

among all patients with STEMI at the admission, D1, D3, and D7. With 44 patients in both groups, we can detect the 0.07 difference of LVEF between two groups with $90 \%$ power [15] (the mean of LVEF in the Peking University Third Hospital from January 2005 to January 2008 is $54.1 \%$, and the SD of LVEF is $8.4 \%$ ). And because this study is nonrandomized, the minimum of each group is doubled. A logistic regression model was used to assess the association between clopidogrel loading dose and LVEF, adjusting for confounders (age, sex, diabetes mellitus, hypertension, anterior myocardial infarction, time from onset to admission, preinfarction angina, corrected TIMI frame count, fasting blood glucose levels, hs-CRP protein, and clopidogrel loading dose). Backward selection procedure with $P$ level more than 0.1 for exclusion from the model and $P$ level less than 0.05 for staying in the model was used to select important predictors. The final models were evaluated by using odds ratio (OR) and 95\% confidence interval (CI). Statistical significance was defined as $P<0.05$. All analyses were performed using SPSS version 15.0 (SPSS, Chicago, IL).

\section{Results}

3.1. Time Course of WBC and Neutrophil $(n=357)$. Figure 1 shows the time course of WBC and neutrophil from admission to D7 after AMI. Total WBC counts on D1 (10.33 $\left.\pm 2.63 \times 10^{9} / \mathrm{L}\right)$ were higher than that at the admission (9.97 $\left.\pm 2.91 \times 10^{9} / \mathrm{L}\right)$, but there was no significance. Neutrophils reached their peak values on $\mathrm{D} 1\left(7.92 \pm 2.60 \times 10^{9} / \mathrm{L}\right)$ and then reduced from D3 to D7 $(F=145.851, P<0.0001)$.

3.2. Baseline Characteristics $(n=357)$. Three hundred and fifty-seven patients enrolled in the study. The ratio of receiving low clopidogrel loading dose to high loading dose was $2.5: 1,2.4: 1,3.2: 1$, and $1.8: 1$ in $2008,2009,2010$, and 2011, respectively. The clinical characteristics and laboratory findings of the patients of different clopidogrel loading dose are summarized in Table 1. PPCI was successfully performed in all patients. The mean interval from the onset of AMI to arrival at the hospital was $4.8 \pm 3.9 \mathrm{~h}$. Risk factor profiles and some baseline clinical parameters such as male percentage, BMI, blood pressure, lipid profile, and concomitant illness were comparable between the two groups. The low clopidogrel loading dose group had higher hs-CRP than the group of high clopidogrel loading dose (Table 1).

3.3. IL-6 and IL-10 Levels in a Subgroup $(n=52)$. In a subgroup including the patients with AMI who were admitted during October 2009 to March $2011(n=52)$, the levels of IL-6 obtained 4-6h after PPCI were significantly higher in the low clopidogrel loading dose group than those found in the group of high clopidogrel loading dose, while the IL-10 levels showed inverse changes (shown in Table 2). On other time points, the levels of IL- 6 and IL-10 were almost comparable between the two groups (Table 2). Baseline clinical parameters were comparable between the two groups (Table 2).

3.4. WBC, Neutrophil, and Platelet Related Indices $(n=357)$. The higher levels of WBC and neutrophil on D1 and D3 were found in patients of low clopidogrel loading dose as shown in Table 3 and Figure 2. Platelet related indices were comparable between the two groups (Table 3 ).

3.5. Heart Function Related Indices $(n=357)$. Heart function related indices of different clopidogrel loading dose were shown in Table 4. Compared with high clopidogrel loading dose group, patients with low loading dose were more likely to suffer from Killip class $>1$. The low clopidogrel loading dose group had lower FS and LVEF than the group of high loading dose. Moreover, patients of low loading dose had higher Nt-proBNP levels, LVESd, and WMSI than the 
TABLE 1: Baseline characteristics.

\begin{tabular}{|c|c|c|c|}
\hline Variable & $\begin{array}{l}\text { Low clopidogrel loading } \\
\text { dose }(300-450 \mathrm{mg}) \\
(n=259)\end{array}$ & $\begin{array}{l}\text { High clopidogrel loading } \\
\text { dose }(600 \mathrm{mg}) \\
(n=98)\end{array}$ & $P$ value \\
\hline Age (yrs) & $61.4 \pm 13.3$ & $61.1 \pm 12.7$ & 0.84 \\
\hline Male sex (\%) & 79.9 & 82.7 & 0.65 \\
\hline Hypertension (\%) & 52.1 & 51.0 & 0.91 \\
\hline Diabetes mellitus (\%) & 35.9 & 28.6 & 0.21 \\
\hline Hypercholesterolemia (\%) & 37.5 & 33.7 & 0.54 \\
\hline Current smoking (\%) & 48.3 & 55.1 & 0.29 \\
\hline Family history of CAD (\%) & 14.7 & 15.3 & 0.87 \\
\hline Body mass index $\left(\mathrm{kg} / \mathrm{m}^{2}\right)$ & $26.1 \pm 4.2$ & $25.5 \pm 3.8$ & 0.45 \\
\hline Anterior infarction (\%) & 51.9 & 41.8 & 0.10 \\
\hline Prior angina (\%) & 65.3 & 55.1 & 0.07 \\
\hline Systolic blood pressure (mm Hg) & $134.3 \pm 25.9$ & $138.8 \pm 31.3$ & 0.23 \\
\hline Diastolic blood pressure ( $\mathrm{mm} \mathrm{Hg}$ ) & $76.8 \pm 16.6$ & $80.9 \pm 19.7$ & 0.13 \\
\hline Time to admission (h) & $4.8 \pm 3.7$ & $4.9 \pm 4.5$ & 0.95 \\
\hline $\begin{array}{l}\text { ST-segment resolution } \geq 50 \% \text { within } 120 \\
\text { minutes after PPCI (\%) }\end{array}$ & 87.6 & 87.6 & 1.00 \\
\hline Corrected TIMI frame count & $32.1 \pm 19.0$ & $30.0 \pm 18.5$ & 0.36 \\
\hline Hemoglobin (g/L) & $144.3 \pm 19.1$ & $145.6 \pm 16.4$ & 0.58 \\
\hline hs-CRP (mg/L) ${ }^{*}$ & $9.11(3.23,23.35)$ & $4.20(1.79,17.97)$ & 0.03 \\
\hline Creatinine $(\mu \mathrm{mol} / \mathrm{L})$ & $86.7 \pm 21.0$ & $87.3 \pm 21.5$ & 0.83 \\
\hline Serum glucose $(\mathrm{mmol} / \mathrm{L})$ & $6.74 \pm 3.01$ & $6.20 \pm 2.37$ & 0.13 \\
\hline Total cholesterol (mmol/L) & $4.69 \pm 1.03$ & $4.63 \pm 0.83$ & 0.58 \\
\hline Triglyceride (mmol/L) & $1.73 \pm 0.92$ & $1.91 \pm 1.19$ & 0.15 \\
\hline $\mathrm{HDL}-\mathrm{C}(\mathrm{mmol} / \mathrm{L})$ & $0.95 \pm 0.24$ & $0.90 \pm 0.20$ & 0.06 \\
\hline LDL-C (mmol/L) & $3.02 \pm 0.90$ & $2.92 \pm 0.73$ & 0.33 \\
\hline IIb/IIIa inhibitors & 32.0 & 28.6 & 0.70 \\
\hline
\end{tabular}

Values represent mean \pm SD or the percent of the patients. ${ }^{*}$ Values represent median with 25 and 75 percentiles.

Note: CAD: coronary artery disease; PPCI: primary percutaneous coronary intervention; hs-CRP: high-sensitive C-reactive protein; HDL-C: high density lipoprotein cholesterol; LDL-C: low density lipoprotein cholesterol.

patients of high loading dose. There was no significant difference in LVEDd, CK, and CK-MB levels between the two groups. Receiving $\beta$-blockers treatment, heart rates, and atrial fibrillation occurrence during the procedures were comparable between the two groups. A logistic regression model was used to assess the association between clopidogrel loading dose and LVEF, adjusting for confounders (age, sex, diabetes mellitus, hypertension, anterior myocardial infarction, time from onset to admission, preinfarction angina, corrected TIMI frame count, fasting blood glucose levels, hs-CRP, and clopidogrel loading dose). After adjusting for the above factors, low clopidogrel loading dose remained an independent predictor of low LVEF (LVEF $\leq 50 \%$ ) as data show in Table 5.

\section{Discussion}

The present study found that, in patients with STEMI undergoing successful PPCI, higher levels of peak neutrophil and lower LVEF were found in patients of low clopidogrel loading dose group ( $300 \mathrm{mg}$ or $450 \mathrm{mg}$ ). After adjusting for the confounders, low clopidogrel loading dose remained an independent predictor of low LVEF (LVEF $\leq 50 \%$ ). Also, the current study observed that total WBC and neutrophil count changed dramatically during the first week: neutrophil reached their peak values on the first day after STEMI and then reduced from the third day to the seventh day; total WBC showed the similar trend.

AMI is universally accompanied by a transient elevation of WBC as part of the inflammatory response [16, 17]. Inflammation has been shown to mediate healing and scar formation after termination of the ischemic event as well as progressive development of tissue damage and ventricular remodeling [18-21]. The first leukocytes which infiltrate the infracted myocardium are neutrophils [19]. Moreover, neutrophils are widely recognized as important mediators of myocardial and vascular injury $[19,22,23]$. Evidence from clinical studies revealed that elevation of baseline neutrophil count is associated with higher in-hospital and short-term mortality in patients with AMI $[24,25]$. In keeping with previous studies, total WBC and neutrophil count in the present study reached their peak values on the first day after 
TABLE 2: Baseline characteristics and IL-6 and IL-10 levels in a subgroup.

\begin{tabular}{|c|c|c|c|}
\hline Variable & $\begin{array}{c}\text { Low clopidogrel loading } \\
\text { dose }(300-450 \mathrm{mg}) \\
(n=32)\end{array}$ & $\begin{array}{l}\text { High clopidogrel loading } \\
\text { dose }(600 \mathrm{mg}) \\
(n=20)\end{array}$ & $P$ value \\
\hline Age (yrs) & $58.4 \pm 15.3$ & $65.7 \pm 12.2$ & 0.17 \\
\hline Male sex (\%) & 84.3 & 55.0 & 0.20 \\
\hline Hypertension (\%) & 37.5 & 40.0 & 0.53 \\
\hline Diabetes mellitus (\%) & 21.9 & 20.0 & 1.00 \\
\hline Hypercholesterolemia (\%) & 31.3 & 25.0 & 1.00 \\
\hline Current smoking (\%) & 50.0 & 35.0 & 0.76 \\
\hline Body mass index $\left(\mathrm{kg} / \mathrm{m}^{2}\right)$ & $26.8 \pm 4.7$ & $24.7 \pm 4.8$ & 0.17 \\
\hline Anterior infarction (\%) & 40.6 & 30.0 & 0.34 \\
\hline \multicolumn{4}{|l|}{ IL-6 (ng/L) } \\
\hline Admission & $7.51(5.13,12.93)$ & $5.86(4.55,8.08)$ & 0.20 \\
\hline 4-6h after PPCI & $10.31(7.90,14.89)$ & $5.96(5.18,10.93)$ & 0.02 \\
\hline $12 \mathrm{~h}$ after PPCI & $8.43(6.88,11.90)$ & $8.52(6.81,13.84)$ & 0.88 \\
\hline $24 \mathrm{~h}$ after PPCI & $7.79(6.16,11.15)$ & $6.70(5.72,8.56)$ & 0.24 \\
\hline $7 \mathrm{~d}$ after PPCI & $9.73(6.40,13.53)$ & $8.13(6.56,12.11)$ & 0.73 \\
\hline Peak value & $13.44(11.94,19.90)$ & $11.54(8.94,24.59)$ & 0.24 \\
\hline \multicolumn{4}{|l|}{ IL-10 (ng/L) } \\
\hline Admission & $18.53(15.54,22.73)$ & $21.78(20.74,23.16)$ & 0.11 \\
\hline 4-6h after PPCI & $16.39(11.24,19.56)$ & $20.64(16.87,22.57)$ & 0.02 \\
\hline $12 \mathrm{~h}$ after PPCI & $18.73(15.70,20.99)$ & $19.06(15.36,21.52)$ & 0.86 \\
\hline $24 \mathrm{~h}$ after PPCI & $18.29(15.05,21.22)$ & $20.72(18.87,22.55)$ & 0.05 \\
\hline $7 \mathrm{~d}$ after PPCI & $17.66(15.59,20.86)$ & $19.44(16.77,21.15)$ & 0.50 \\
\hline Peak value & $21.35(20.00,24.33)$ & $22.71(21.58,24.60)$ & 0.12 \\
\hline
\end{tabular}

Values represent mean \pm SD or median with 25 and 75 percentiles.

Note: CAD: coronary artery disease; PCI: percutaneous coronary intervention; hs-CRP: high-sensitive C-reactive protein; HDL-C: high density lipoprotein cholesterol; LDL-C: low density lipoprotein cholesterol; IL-6: interleukin-6; IL-10: interleukin-10.

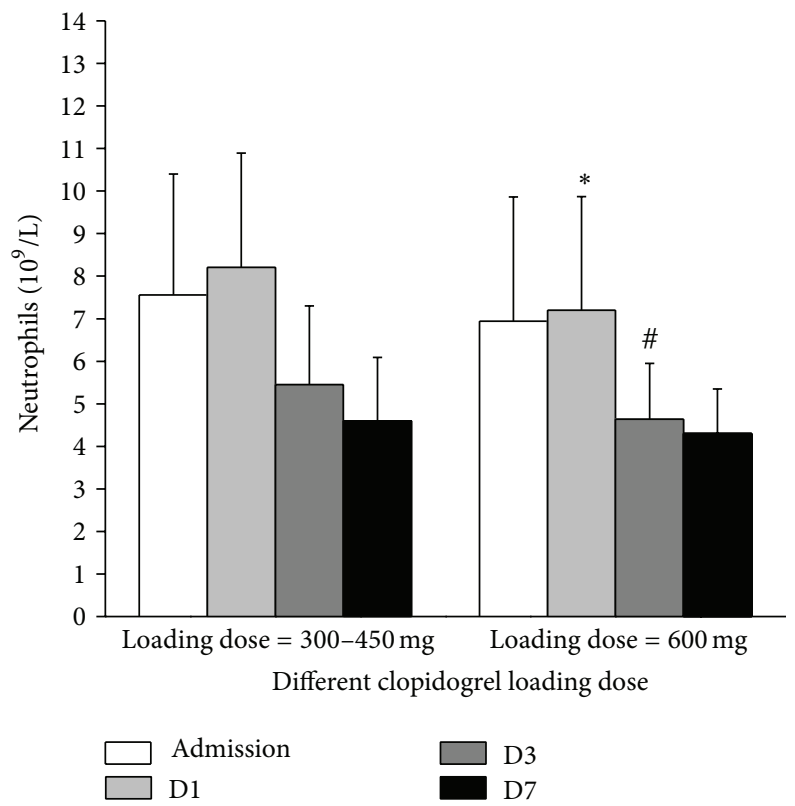

Figure 2: Comparison of neutrophil between different clopidogrel loading doses (low clopidogrel loading dose: $300-450 \mathrm{mg}$, $n=259$; high clopidogrel loading dose: $600 \mathrm{mg}, n=98)$ at different time points during the first week $(n=357)$. $*$ Represents $P<0.05$ compared with low clopidogrel loading dose (300-450 mg) on D1 and \# represents $P<0.05$ compared with low clopidogrel loading dose (300-450 mg) on D3. 
TABLE 3: WBC, neutrophil, and platelet related indices.

\begin{tabular}{|c|c|c|c|}
\hline Variable & $\begin{array}{c}\text { Low clopidogrel loading } \\
\text { dose }(300-450 \mathrm{mg}) \\
(n=259)\end{array}$ & $\begin{array}{l}\text { High clopidogrel loading } \\
\text { dose }(600 \mathrm{mg}) \\
(n=98)\end{array}$ & $P$ value \\
\hline \multicolumn{4}{|c|}{ Total WBC $\left(\times 10^{9} / \mathrm{L}\right)$} \\
\hline Admission & $10.14 \pm 2.87$ & $9.47 \pm 2.99$ & 0.07 \\
\hline D1 & $10.58 \pm 2.66$ & $9.70 \pm 2.43$ & 0.01 \\
\hline D3 & $8.15 \pm 2.11$ & $7.42 \pm 1.76$ & 0.01 \\
\hline D7 & $7.23 \pm 1.84$ & $6.94 \pm 1.52$ & 0.25 \\
\hline \multicolumn{4}{|c|}{ Neutrophil $\left(\times 10^{9} / \mathrm{L}\right)$} \\
\hline Admission & $7.56 \pm 2.84$ & $6.94 \pm 2.92$ & 0.09 \\
\hline D1 & $8.21 \pm 2.68$ & $7.20 \pm 2.67$ & 0.001 \\
\hline D3 & $5.45 \pm 1.85$ & $4.64 \pm 1.31$ & $<0.0001$ \\
\hline D7 & $4.60 \pm 1.49$ & $4.30 \pm 1.05$ & 0.08 \\
\hline \multicolumn{4}{|c|}{ Platelet counts $\left(\times 10^{9} / \mathrm{L}\right)$} \\
\hline Admission & $225.5 \pm 60.0$ & $208.2 \pm 56.3$ & 0.02 \\
\hline D1 & $209.2 \pm 54.5$ & $197.7 \pm 57.2$ & 0.08 \\
\hline D3 & $191.0 \pm 50.3$ & $178.4 \pm 56.6$ & 0.08 \\
\hline D7 & $222.9 \pm 54.2$ & $214.5 \pm 55.5$ & 0.29 \\
\hline \multicolumn{4}{|l|}{ MPV (fL) } \\
\hline Admission & $10.16 \pm 0.99$ & $10.05 \pm 1.12$ & 0.39 \\
\hline D1 & $8.31 \pm 0.89$ & $8.48 \pm 0.89$ & 0.10 \\
\hline D3 & $8.53 \pm 0.94$ & $8.56 \pm 0.90$ & 0.82 \\
\hline D7 & $8.38 \pm 0.87$ & $8.53 \pm 0.95$ & 0.25 \\
\hline
\end{tabular}

Values represent mean \pm SD.

Note: WBC: white blood cell; D1: the first day after AMI; D3: the third day; D7: the seventh day; MPV: mean platelet volume.

AMI. Based on what was discussed earlier, peak leukocyte and neutrophil count might better reflect the magnitude of the inflammatory response to myocardial necrosis [16]. PPCI were performed in all patients in this study. Due to the fact that the "no-reflow" phenomenon has also been directly linked to neutrophil localization, the neutrophil peak may be related to the reperfusion injury [26].

In the present study higher levels of peak neutrophil and lower LVEF were found in patients of low clopidogrel loading dose group. As has been demonstrated in clinical experiments, increased neutrophil at the admission in patients with AMI was related to the early development of congestive heart failure $[3,24]$. There is abundant evidence that leukocytes contribute to impairment of myocardial function and adverse ventricular remodeling in the postinfarction setting [20, 21]. Neutrophils are known to accumulate in the ischemic and reperfused areas and might release proteolytic enzymes or reactive oxygen species to injure surrounding myocytes [19]. Moreover, the "no-reflow" phenomenon could be interpreted as a consequence of neutrophil and platelet localization [26]. It is well known that the no-reflow phenomenon is associated with poor left ventricular function [27, 28].

Platelet activation plays a crucial role in initiating and propagating thrombosis, and antiplatelet therapy is the key management of AMI $[5,6]$. Experimental studies have demonstrated that there are increased interactions between platelets and leukocytes in the pathophysiology of AMI [1,
2]. Both leukocytes and platelets adhere to the endothelial lining at the culprit site of coronary artery occlusion [29]. In response to ischemia and reperfusion, neutrophils migrate into the vessel wall and microvasculature and secrete a variety of autacoids, which lead to vasoconstriction and platelet aggregation, such as thromboxane-B2 and leukotrienes-B4 [19]. Interactions between leukocytes and platelets amplify through upregulation of the CD11b/18 receptor on the leukocyte surface, inducing further release of cytokines and procoagulants [30]. In addition, platelet-neutrophils aggregates may also contribute to microvascular plugging and microembolization and mediate the "no-reflow" phenomenon [26].

Clopidogrel, an ADP receptor antagonist, is established to reduce the incidence of stroke, myocardial ischemia, or vascular death $[5,6,31]$. Several clinical trials have demonstrated that a loading dose of $600 \mathrm{mg}$ clopidogrel significantly reduces the risk of major cardiovascular events (including death, ACS, revascularization, and stroke) without increase in major bleeding compared to $300 \mathrm{mg}$ in patients undergoing PPCI $[7,8]$. Since clopidogrel has inhibitory effect on platelets in a dose-dependent manner, dosing of clopidogrel is an important variable influencing the patient's prognosis [32]. Rapid and sufficient platelet inhibition is achieved $2 \mathrm{~h}$ after a $600 \mathrm{mg}$ loading dose of clopidogrel [33].

A large scale study including 56,944 patients showed that clopidogrel was associated with reduced mortality in patients with heart failure who do not undergo PCI after their 
TABLE 4: Heart function related indices.

\begin{tabular}{|c|c|c|c|}
\hline Variable & $\begin{array}{c}\text { Low clopidogrel loading } \\
\text { dose }(300-450 \mathrm{mg}) \\
(n=259)\end{array}$ & $\begin{array}{l}\text { High clopidogrel loading } \\
\text { dose }(600 \mathrm{mg}) \\
(n=98)\end{array}$ & $P$ value \\
\hline Peak CK (IU/L) & $2350.4 \pm 1933.7$ & $2046.9 \pm 1766.0$ & 0.18 \\
\hline Peak CK-MB (IU/L) & $228.2 \pm 147.5$ & $210.7 \pm 148.9$ & 0.32 \\
\hline Nt-proBNP (pg/mL) & $2166.8 \pm 2922.0$ & $1112.8 \pm 1176.7$ & $<0.0001$ \\
\hline Killip class > $1(\%)$ & 25.1 & 12.2 & 0.01 \\
\hline \multicolumn{4}{|l|}{ Echocardiographic findings } \\
\hline Heart rates (beat/min) & $75.6 \pm 11.3$ & $74.7 \pm 9.6$ & 0.28 \\
\hline Atrial fibrillation (\%) & 21.0 & 18.6 & 0.66 \\
\hline On $\beta$-blocker treatment (\%) & 73.1 & 70.0 & 0.33 \\
\hline $\operatorname{LVEDd}(\mathrm{mm})$ & $49.8 \pm 5.1$ & $49.1 \pm 4.8$ & 0.26 \\
\hline LVESd (mm) & $35.0 \pm 5.8$ & $33.4 \pm 5.2$ & 0.02 \\
\hline FS (\%) & $29.9 \pm 7.1$ & $31.9 \pm 7.5$ & 0.02 \\
\hline $\operatorname{LVEF}(\%)$ & $53.2 \pm 8.4$ & $56.4 \pm 7.9$ & 0.002 \\
\hline WMSI & $1.56 \pm 0.21$ & $1.47 \pm 0.23$ & 0.001 \\
\hline
\end{tabular}

Values represent mean \pm SD or the percent of the patients.

Note: CK: creatine kinase; CK-MB: creatine kinase-MB; Nt-proBNP: N-terminal pro B-type natriuretic peptide; LVEDd: left ventricular end diastolic dimension; LVESd: left ventricular end systolic dimension; FS: fractional shortening; LVEF: left ventricular ejection fraction; WMSI: wall motion score index.

TABLE 5: Multiple logistic analysis of low LVEF (LVEF $\leq 50 \%)$.

\begin{tabular}{lccc}
\hline Variable & OR & $95 \%$ CI & $P$ value \\
\hline Anterior infarction & 5.15 & $2.89-9.20$ & $<0.0001$ \\
Diabetes mellitus & 2.48 & $1.40-4.41$ & 0.002 \\
Time to admission & 0.92 & $0.86-0.98$ & 0.02 \\
$\begin{array}{l}\text { Low clopidogrel loading } \\
\text { dose (300-450 mg) }\end{array}$ & 1.97 & $1.03-3.79$ & 0.04 \\
\hline
\end{tabular}

first-time AMI, whereas this association was not apparent in patients without heart failure [34]. Compared with application of aspirin and continuous infusion of unfractionated heparin, the intensified clopidogrel loading and maintenance doses provided early reperfusion and suppression of inflammatory response in patients with standard fibrinolysis therapy [24]. Specifically, an antiplatelets therapy, such as clopidogrel, has been proven to reduce circulating plateletleukocyte conjugates [10].

It has been shown that platelet size, measured as mean platelet volume (MPV), is related to its reactivity [35]. In the present study, MPV was comparable between the low and high clopidogrel loading dose groups $(n=357)$. There was no difference in the IL- 6 and IL-10 levels between the low and high clopidogrel loading dose groups on admission in a subgroup $(n=52)$, whereas $4-6 \mathrm{~h}$ after PPCI the levels of IL-6 were higher in the low clopidogrel loading dose group than those found in the group of high loading dose, the same time at which the IL-10 levels showed inverse changes. IL-6 and IL-10 have been established as important pro- and antiinflammatory cytokines during acute myocardial ischemia $[36,37]$. As discussed in the previous section, antiplatelets therapies, such as clopidogrel, may also exhibit some antiinflammatory properties, thereby potentially offering benefits beyond inhibition of platelet activation [38].

Clopidogrel application before primary PCI (in the emergency department or the intensive care unit) was independently associated with a higher TIMI myocardial perfusion rate [39]. Based on the multiple effects of clopidogrel and its dose-dependent manner, it is easy to understand that high loading dosage of clopidogrel was associated with lower peak neutrophil and better left ventricular systolic function. Until then, on the basis of our observational data, as well as those from previous studies of patients with STEMI, it would seem prudent to treat patients with STEMI with high-dose clopidogrel.

The major limitation of the present study was its nonrandomized nature; the clopidogrel loading dose was left to the discretion of the treating physician. Thus, although the treatment effects reflect real-life practice, they might also reflect physician bias. In an attempt to control for potential confounders, we performed a multivariate analysis, the results of which support the unadjusted results. As the current study excluded the patients who did not perform primary PCI, the results of the present study only reflect the special population. Last, because of small sample size, the analysis of subgroup and in-hospital cardiovascular events could not be performed.

\section{Conclusion}

Higher peak neutrophil count and poor left ventricular systolic function were found in low clopidogrel loading dose. Furthermore, low loading dose of clopidogrel remained a significant predictor of low LVEF after adjusting for potential 
confounders. These results suggest an important role of clopidogrel loading dose in the improvement of left ventricular function and high loading dose may exhibit better antiinflammatory properties.

\section{Conflict of Interests}

The authors declare that there is no conflict of interests regarding the publication of this paper.

\section{Authors' Contribution}

Xinyu Wang and Haiyi Yu contributed equally to this work.

\section{Acknowledgments}

This work was supported by Beijing Natural Science Foundation (7144254 to Xinyu Wang), the National Natural Science Foundation of China (81370317 to Wei Gao), and the Projects of International Cooperation and Exchanges NSFC (30910103902 to Youyi Zhang).

\section{References}

[1] E. Falk, M. Nakano, J. F. Bentzon, A. V. Finn, and R. Virmani, "Update on acute coronary syndromes: the pathologists' view," European Heart Journal, vol. 34, no. 10, pp. 719-728, 2013.

[2] G. Vilahur, O. Juan-Babot, E. Peña, B. Oñate, L. Casaní, and L. Badimon, "Molecular and cellular mechanisms involved in cardiac remodeling after acute myocardial infarction," Journal of Molecular and Cellular Cardiology, vol. 50, no. 3, pp. 522-533, 2011.

[3] L. Kyne, J. M. Hausdorff, E. Knight, L. Dukas, G. Azhar, and J. Y. Wei, "Neutrophilia and congestive heart failure after acute myocardial infarction," The American Heart Journal, vol. 139, no. 1 I, pp. 94-100, 2000.

[4] R. Dragu, S. Khoury, R. Zuckerman et al., "Predictive value of white blood cell subtypes for long-term outcome following myocardial infarction," Atherosclerosis, vol. 196, pp. 405-412, 2008.

[5] Z. M. Chen, L. X. Jiang, Y. P. Chen et al., "Addition of clopidogrel to aspirin in 45852 patients with acute myocardial infarction: randomised placebo-controlled trial," The Lancet, vol. 366, no. 9497, pp. 1607-1621, 2005.

[6] M. S. Sabatine, C. H. McCabe, C. M. Gibson, and C. P. Cannon, "Design and rationale of Clopidogrel as Adjunctive Reperfusion Therapy-Thrombolysis in Myocardial Infarction (CLARITYTIMI) 28 trial," American Heart Journal, vol. 149, no. 2, pp. 227233, 2005.

[7] G. Dangas, R. Mehran, G. Guagliumi et al., "Role of clopidogrel loading dose in patients with ST-segment elevation myocardial infarction undergoing primary angioplasty: results from the HORIZONS-AMI (harmonizing outcomes with revascularization and stents in acute myocardial infarction) trial," Journal of the American College of Cardiology, vol. 54, no. 15, pp. 14381446, 2009.

[8] J. M. Siller-Matula, K. Huber, G. Christ et al., "Impact of clopidogrel loading dose on clinical outcome in patients undergoing percutaneous coronary intervention: a systematic review and meta-analysis," Heart, vol. 97, no. 2, pp. 98-105, 2011.
[9] T. Heitzer, V. Rudolph, E. Schwedhelm et al., "Clopidogrel improves systemic endothelial nitric oxide bioavailability in patients with coronary artery disease: evidence for antioxidant and antiinflammatory effects," Arteriosclerosis, Thrombosis, and Vascular Biology, vol. 26, no. 7, pp. 1648-1652, 2006.

[10] V. Evangelista, S. Manarini, G. Dell'Elba et al., "Clopidogrel inhibits platelet-leukocyte adhesion and platelet-dependent leukocyte activation," Thrombosis and Haemostasis, vol. 94, no. 3, pp. 568-577, 2005.

[11] M. Mariani, R. Fetiveau, E. Rossetti et al., "Significance of total and differential leucocyte count in patients with acute myocardial infarction treated with primary coronary angioplasty," European Heart Journal, vol. 27, no. 21, pp. 2511-2515, 2006.

[12] C. M. Gibson, C. P. Cannon, W. L. Daley et al., "TIMI frame count: A quantitative method of assessing coronary artery flow," Circulation, vol. 93, no. 5, pp. 879-888, 1996.

[13] T. Killip III and J. T. Kimball, “Treatment of myocardial infarction in a coronary care unit. A two year experience with 250 patients," The American Journal of Cardiology, vol. 20, no. 4, pp. 457-464, 1967.

[14] M. D. Cerqueira, N. J. Weissman, V. Dilsizian et al., "American Heart Association writing group on myocardial segmentation and registration for cardiac imaging. Standardized myocardial segmentation and nomenclature for tomographic imaging of the heart: a statement for healthcare professionals from the cardiac imaging committee of the council on clinical cardiology of the American Heart Association," Circulation, vol. 105, pp. 539-542, 2002.

[15] S. C. Chow, J. Shao, and H. Wang, Sample Size Calculation in Clinical Research, Marcel Dekker, New York, NY, USA, 2003.

[16] B. S. Coller, "Leukocytosis and ischemic vascular disease morbidity and mortality: is it time to intervene?" Arteriosclerosis, Thrombosis, and Vascular Biology, vol. 25, no. 4, pp. 658-670, 2005.

[17] S. P. Thomson, R. J. Gibbons, P. A. Smars et al., "Incremental value of the leukocyte differential and the rapid creatine kinaseMB isoenzyme for the early diagnosis of myocardial infarction," Annals of Internal Medicine, vol. 122, no. 5, pp. 335-341, 1995.

[18] M. Nian, P. Lee, N. Khaper, and P. Liu, "Inflammatory cytokines and postmyocardial infarction remodeling," Circulation Research, vol. 94, no. 12, pp. 1543-1553, 2004.

[19] N. G. Frangogiannis, C. W. Smith, and M. L. Entman, "The inflammatory response in myocardial infarction," Cardiovascular Research, vol. 53, no. 1, pp. 31-47, 2002.

[20] N. Vasilyev, T. Williams, M. L. Brennan et al., "Myeloperoxidase-generated oxidants modulate left ventricular remodeling but not infarct size after myocardial infarction," Circulation, vol. 112, no. 18, pp. 2812-2820, 2005.

[21] A. T. Askari, M. Brennan, X. Zhou et al., "Myeloperoxidase and plasminogen activator inhibitor 1 play a central role in ventricular remodeling after myocardial infarction," Journal of Experimental Medicine, vol. 197, no. 5, pp. 615-624, 2003.

[22] J. E. Jordan, Z. Zhao, and J. Vinten-Johansen, "The role of neutrophils in myocardial ischemia-reperfusion injury," Cardiovascular Research, vol. 43, no. 4, pp. 860-878, 1999.

[23] K. S. Kilgore and B. R. Lucchesi, "Neutrophils and altered myocardial function," The American Heart Journal, vol. 139, no. 1 I, pp. 32-34, 2000.

[24] M. O’Donoghue, D. A. Morrow, C. P. Cannon et al., "Association between baseline neutrophil count, clopidogrel therapy, 
and clinical and angiographic outcomes in patients with STelevation myocardial infarction receiving fibrinolytic therapy," European Heart Journal, vol. 29, no. 8, pp. 984-991, 2008.

[25] H. V. Barron, S. D. Harr, M. J. Radford, Y. Wang, and H. M. Krumholz, "The association between white blood cell count and acute myocardial infarction mortality in patients $\geq 65$ years of age: findings from the cooperative cardiovascular project," Journal of the American College of Cardiology, vol. 38, no. 6, pp. 1654-1661, 2001.

[26] N. Botto, S. Sbrana, G. Trianni et al., "An increased plateletleukocytes interaction at the culprit site of coronary artery occlusion in acute myocardial infarction: a pathogenic role for "no-reflow" phenomenon?" International Journal of Cardiology, vol. 117, no. 1, pp. 123-130, 2007.

[27] C. M. Gibson, C. P. Cannon, S. A. Murphy, S. J. Marble, H. V. Barron, and E. Braunwald, "Relationship of the TIMI myocardial perfusion grades, flow grades, frame count, and percutaneous coronary intervention to long-term outcomes after thrombolytic administration in acute myocardial infarction," Circulation, vol. 105, no. 16, pp. 1909-1913, 2002.

[28] L. Bolognese, N. Carrabba, G. Parodi et al., "Impact of microvascular dysfunction on left ventricular remodeling and long-term clinical outcome after primary coronary angioplasty for acute myocardial infarction," Circulation, vol. 109, no. 9, pp. 1121-1126, 2004.

[29] G. Bazzoni, E. Dejana, and A. Del Maschio, "Platelet-neutrophil interactions. Possible relevance in the pathogenesis of thrombosis and inflammation," Haematologica, vol. 76, no. 6, pp. 491499, 1991.

[30] V. Evangelista, S. Manarini, R. Sideri et al., "Platelet/polymorphonuclear leukocyte interaction: P-selectin triggers proteintyrosine phosphorylation-dependent CD11b/CD18 adhesion: role of PSGL-1 as a signaling molecule," Blood, vol. 93, no. 3, pp. 876-885, 1999.

[31] CAPRIE Steering Committee, "A randomised, blinded, trial of clopidogrel versus aspirin in patients at risk of ischaemic events (CAPRIE)," The Lancet, vol. 348, no. 9038, pp. 1329-1339, 1996.

[32] T. Cuisset, C. Frere, J. Quilici et al., "Benefit of a 600-mg loading dose of clopidogrel on platelet reactivity and clinical outcomes in patients with non-ST-segment elevation acute coronary syndrome undergoing coronary stenting," Journal of the American College of Cardiology, vol. 48, no. 7, pp. 1339-1345, 2006.

[33] W. Hochholzer, D. Trenk, D. Frundi et al., "Time dependence of platelet inhibition after a 600-mg loading dose of clopidogrel in a large, unselected cohort of candidates for percutaneous coronary intervention," Circulation, vol. 111, no. 20, pp. 25602564, 2005.

[34] L. Bonde, R. Sorensen, E. L. Fosbøl et al., "Increased mortality associated with low use of clopidogrel in patients with heart failure and acute myocardial infarction not undergoing percutaneous coronary intervention: a nationwide study," Journal of the American College of Cardiology, vol. 55, no. 13, pp.1300-1307, 2010.

[35] L. Vizioli, S. Muscari, and A. Muscari, "The relationship of mean platelet volume with the risk and prognosis of cardiovascular diseases," International Journal of Clinical Practice, vol. 63, no. 10, pp. 1509-1515, 2009.

[36] H. S. Sharma and D. K. Das, "Role of cytokines in myocardial ischemia and reperfusion," Mediators of Inflammation, vol. 6, no. 3, pp. 175-183, 1997.
[37] A. L. Pasqui, M. Di Renzo, S. Maffei et al., "Pro/Antiinflammatory cytokine imbalance in postischemic left ventricular remodeling," Mediators of Inflammation, vol. 2010, Article ID 974694, 8 pages, 2010.

[38] M. Akbulut, M. Kutlu, Y. Ozbay et al., "Efficacy of clopidrogel on reperfusion and high-sensitivity c-reactive protein in patients with acute myocardial infarction," Mediators of Inflammation, vol. 2009, Article ID 932515, 5 pages, 2009.

[39] E. I. Lev, R. Kornowski, H. Vaknin-Assa et al., "Effect of clopidogrel pretreatment on angiographic and clinical outcomes in patients undergoing primary percutaneous coronary intervention for ST-elevation acute myocardial infarction," American Journal of Cardiology, vol. 101, no. 4, pp. 435-439, 2008. 


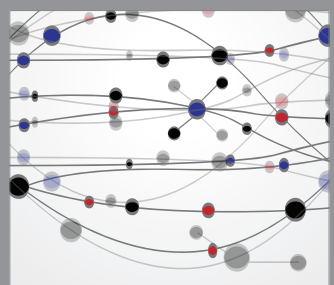

The Scientific World Journal
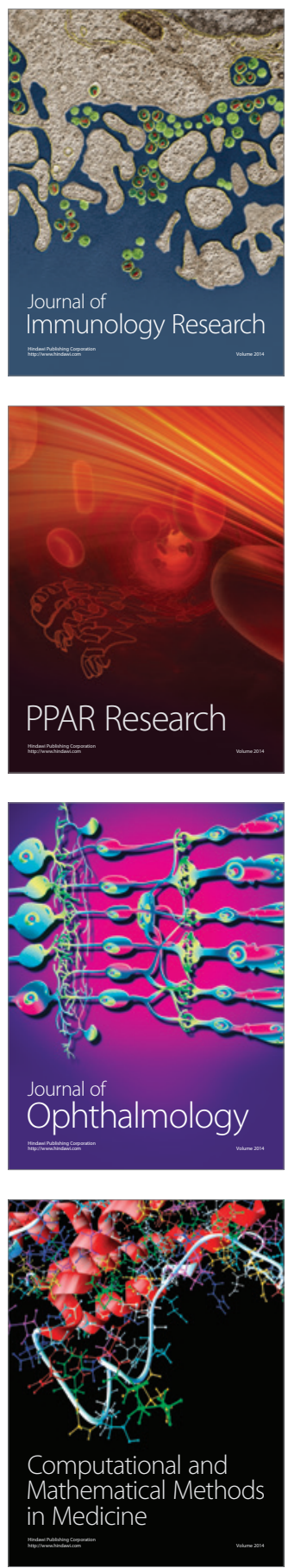

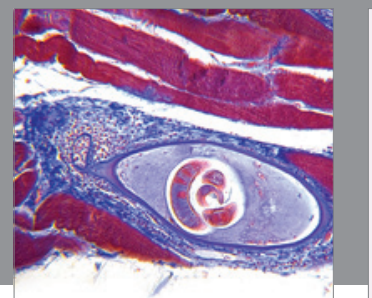

Gastroenterology

Research and Practice
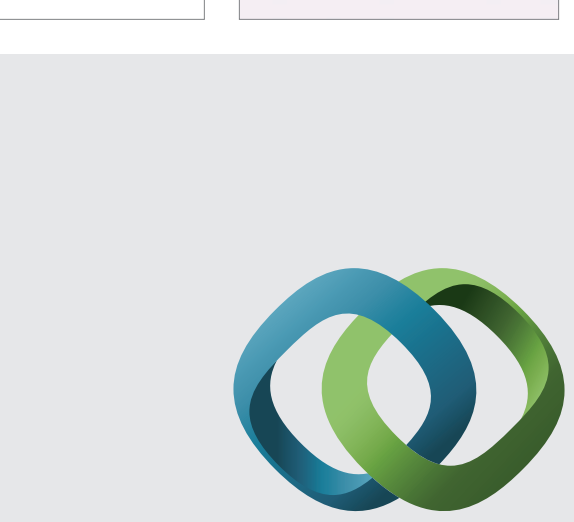

\section{Hindawi}

Submit your manuscripts at

http://www.hindawi.com
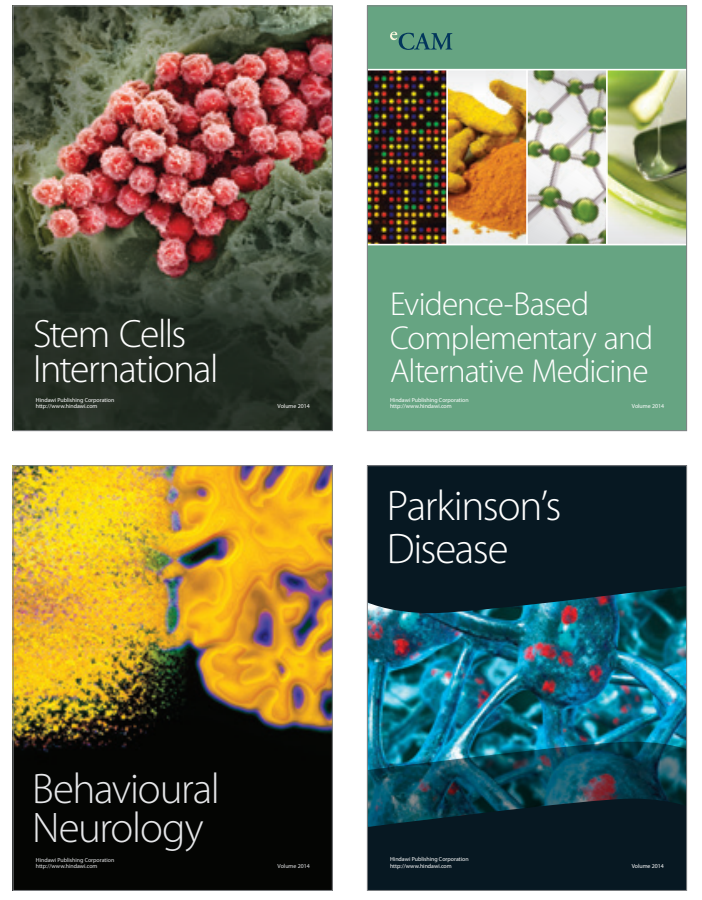
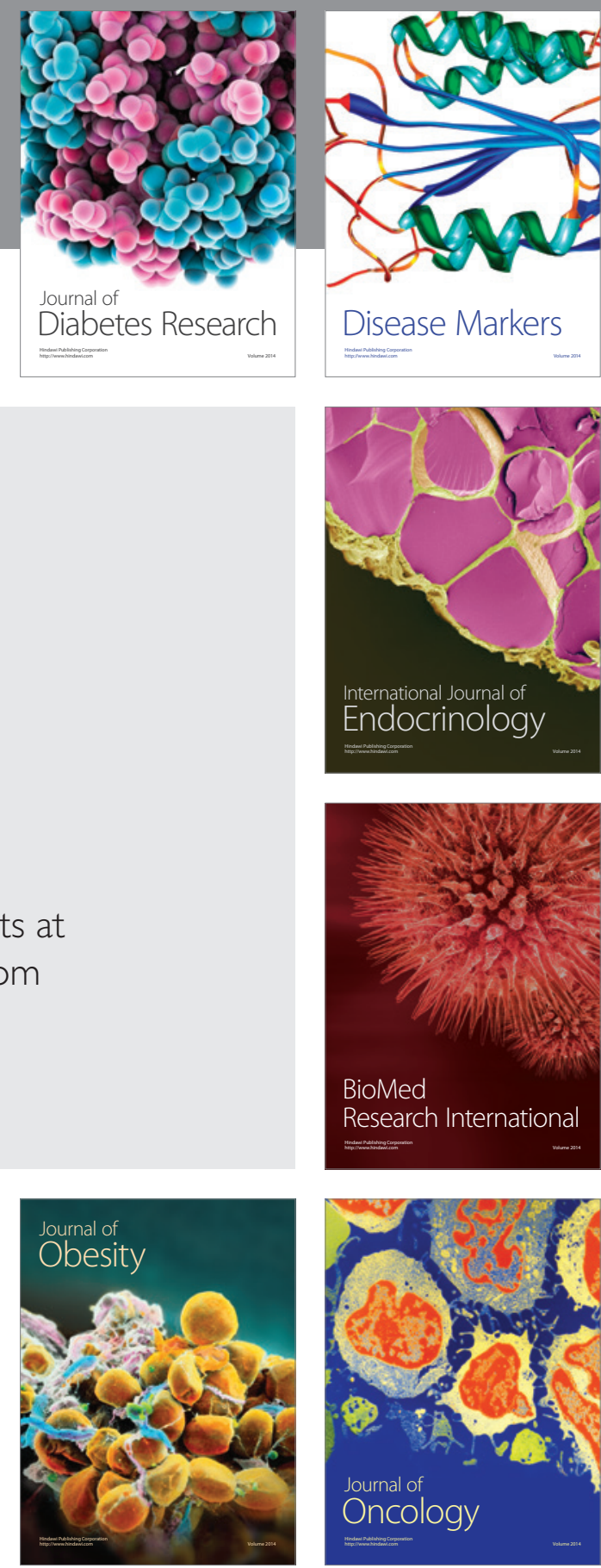

Disease Markers
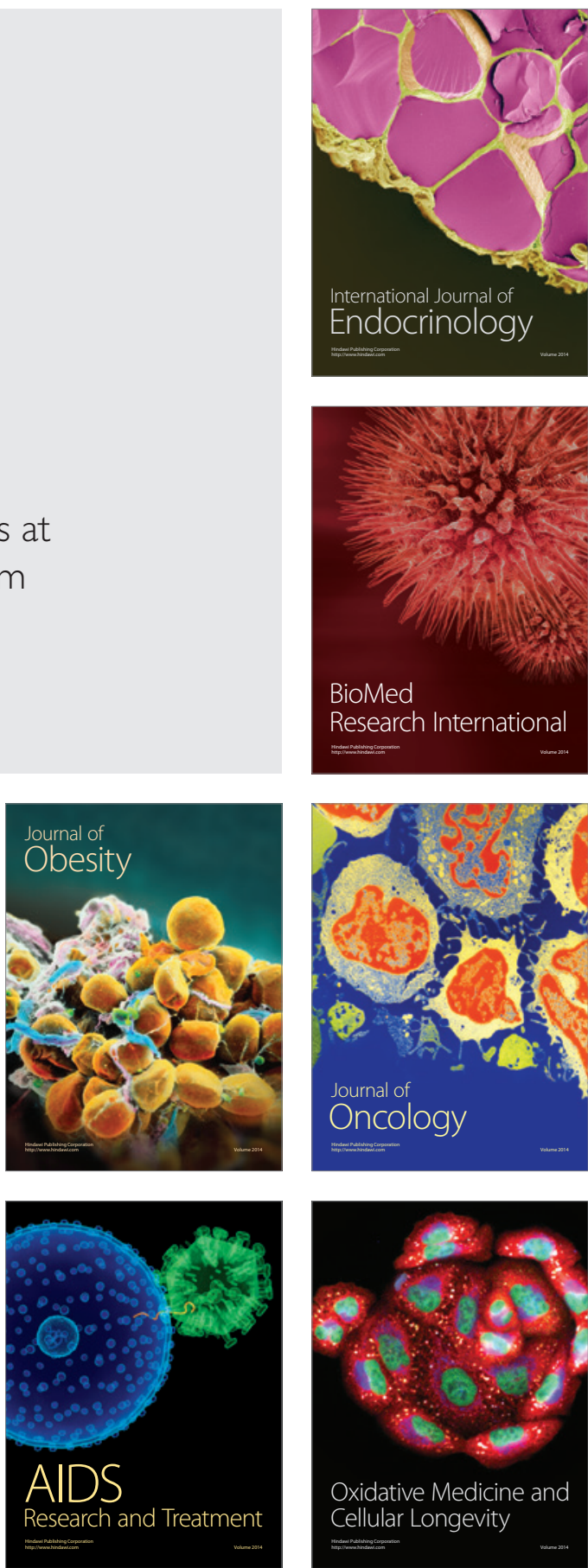